\title{
Comparison of Intubated Versus Non-Intubated Techniques in Video-Assisted Thoracoscopic Sympathectomy
}

Etik Kurul Onayı: Ankara Onkoloji Eğitim ve Araştırma Hastanesi'nden yerel etik kurul onayı alınmıştır (05.02.2020/2020-02/540).

Çıkar çatışması: Çıkar çatışması yoktur.

Finansal Destek: Bu çalışma, herhangi bir fon tarafından desteklenmemiştir.

Hasta Onamı: Hastalardan aydınlatıımış onam alınmıştır.
Ethics Committee: Ankara Oncology Training and Research Hospital Local Ethics Commitee approval was obtained (05.02.2020-2020-02/540).

Conflict of interest: There is no conflict of interest.

Funding: This study was not supported by any funding.

Informed consent: Informed consent was obtained from the patients.

Cite as: Turan U, Şenkal S. Video yardımlı torakoskopik sempatektomilerde entübe ve non-entübe tekniklerin karşılaştırılması. GKDA Derg. 2020;26(3):123--32.

Öz

Amaç: Sempatektomi, plevral biyopsi, akciğer parankim biyopsisi, plöredezis ve büllektomi gibi minör Video Yardımlı Torakoskopik Cerrahi (VATS) prosedürlerde, klasik entübasyonla tek akciğer ventilasyon tekniğine alternatif olarak Non-Entübe VATS (NIVATS) tekniği kullanımı giderek artmak tadır. Amacımız, bilateral ve uniportal sempatektomilerde klasik entübasyon yöntemi ile supraglottik bir hava yolu aracıyla spontan solunum korunarak uygulanan NIVATS tekniğini, uygulanabilirlik ve perioperatif etkiler açısından karşılaștırmaktı.

Yöntem: Hastalar, Laringeal Mask Airway (LMA) veya Çift Lümenli Tüp (ÇLT) kullanımına göre Grup LMA (n: 20) ve Grup ÇLT (n: 20) olarak 2 grupta değerlendirildi. Her iki grubun demografik verileri, anestezi ve cerrahi süreleri, solunum parametreleri, cerrahi zorluk değerlendirmesi, anestezi sonras bakım ünitesindeki ağrı skoru, analjezik ajan kullanımı ve kalış süresi; postoperatif oral alım ve mobilizasyon başlangıç süreleri, postoperatif takiplerindeki ağrı skorları, hava kaçağı, pnömotoraks, hava kaçağı, boğaz ağrısı, bulantı-kusma komplikasyonları ve hastanede kalış süreleri karşılasstırıldı.

Bulgular: Anestezi indüksiyon süresi LMA grubunda belirgin olarak düşük bulundu $(p<0.001)$. Maksimum solunum sonu karbondioksit ( $\left.\mathrm{EtCO}_{2}\right)$, minimum periferal oksijen satürasyonu (SpO $)_{2}$, maksimum solunum sayısı LMA grubunda anlamlı olarak yüksekti $(p<0.001)$. Ortalama inspire edilen oksijen fraksiyonu (FiO ${ }_{2}$ ) ve ortalama tidal volüm ÇLT grubunda anlamlı olarak yüksek bulundu $(p<0.05)$. Cerrahi uygulanabilirlik açısından 2 grup arasında istatistiksel olarak anlamlı bir fark görülmedi. Postoperatif dönemde oral beslenmeye bașlama ve mobilize olma zamanları arasında anlamIı fark bulundu ( $p<0.05)$. Diğer ağrı skorları, postoperatif komplikasyonlar ve hastanede kalış süreleri arasında istatistiksel olarak anlamlı bir fark görülmedi.

Sonuç: VATS Sempatektomi olgularında LMA ile spontan solunum korunarak iyatrojenik açık pnömotoraks oluşturulduğunda NIVATS anestezi tekniğinin etkili ve güvenli bir şekilde kullanılabileceği düşüncesindeyiz.

Anahtar kelimeler: laringeal maske, NIVATS, sempatektomi, tek akciğer ventilasyonu, VATS

\section{ABSTRACT}

Objective: The use of Non-Intubated Video Assisted Thoracoscopic Surgery (NIVATS) technique is gradually increasing as an alternative method to classical intubation in minor Video Assisted Thoracoscopic Surgeries (VATS) such as sympathectomy, pleural biopsy, lung parenchymal biopsy, pleurodesis and bullectomy. Our aim was to compare a NIVATS technique with the classical intubation method applied in bilateral and uniportal sympathectomies in terms of feasibility and perioperative effects.

Method: According to the use of Laryngeal Mask Airway (LMA) or Double Lumen Tube (DLT), the patients were evaluated in two groups as Group LMA (n: 20) and Group DLT (n: 20). Demographic data, anesthesia and surgery times, respiratory parameters, surgical feasibility assessment, the postoperative oral intake and mobilization starting times, pain scores, sore throat, nausea-vomiting, air leak, pneumothorax at postoperative follow-ups, and length of hospital stay were compared between groups.

Results: Anesthesia induction time was significantly lower in the LMA group ( $p<0.001)$. Maximum EtCO2, and minimum SpO saturations, and maximum respiratory rates were significantly higher in the LMA group $(p<0.001)$. Mean FiO and mean TV were significantly higher in the DLT group $(p<0.05)$. There was no statistically significant difference between the two groups in terms of surgical feasibility. There was a significant difference between the onset of oral feeding and mobilizing $(p<0.05)$. There was no statistically significant difference between pain scores, postoperative complications and length of hospital stay.

Conclusion: Our data suggest that LMA NIVATS technique by preserving spontaneous ventilation and establishing iatrogenic open pneumothorax is a feasible and safe strategy in cases with VATS sympathectomy.

Keywords: laryngeal masks, NIVATS, sympathectomy, one-lung ventilation, VATS
Received/Geliş: 28.07 .2020

Accepted/Kabul: 26.08 .2020

Published Online/Online yayın: 21.09.2020

Serkan Şenkal

Sağlık Bilimleri Üniversitesi Gülhane Tıp Fakültesi

Ankara - Türkiye - senkalserkan@gmail.com ORCiD: 0000-0001-8196-3834

U. Turan 0000-0002-8475-2175 Sağlık Bilimleri Üniversitesi Gülhane Tıp Fakültesi Ankara - Türkiye

(C) Telif hakkı Göğüs Kalp Damar Anestezi ve Yoğun Bakım Derneği'ne aittir. Logos Tıp Yayıncılık tarafindan yayınlanmaktadır. Bu dergide yayınlanan bütün makaleler Creative Commons Atff-Gayri Ticari 4.0 Uluslararası Lisansı ile lisanslanmıştı. 


\section{Giriş}

Sempatektomi, plevral veya akciğer parankim biyopsisi, plöredezis ve büllektomi gibi minör Video Yardımlı Torakoskopik Cerrahi (VATS) prosedürlerde, Non-Entübe VATS (NIVATS) anestezi tekniğinin klasik entübasyona alternatif olarak kullanımı giderek artmaktadır ${ }^{[1]}$. NIVATS tekniğinde entübasyon uygulanmadığı için elde edilen kazanımlar yanında, genel anestezinin amnezi, analjezi ve arefleksi gibi avantajları ilgi çekicidir ${ }^{[2]}$.

Minör VATS prosedürlerinde klasik anestezi yönetiminde, tek akciğer ventilasyonu sağlamak için hava yolu aracı olarak çift lümenli tüp (ÇLT) veya endobronşiyal blokör (EBB) kullanılır. ÇLT ve EBB ile tek akciğer ventilasyonunda; trakeobronşiyal yapıların hasarlanması, kanama, tüpün malpozisyonu, dependan ve non-dependan akciğerde barotravma, volutravma, atelektotravma ve biyotravma ve postoperatif solunumsal komplikasyonlar görülebilir ${ }^{[3-7]}$. Uygun ÇLT seçimi ve genel anestezi yönetimi bu komplikasyonların sıklı̆ı̆ını ve şiddetini etkileyebilir. Minör VATS prosedürlerinde ÇLT ile tek akciğer ventilasyonuna alternatif olarak NIVATS teknikler de kullanılabilir ${ }^{[8]}$. NIVATS tekniği; entübe etmeden ve hava yolu aracı kullanmadan rejyonal anestezi teknikleriyle kombine olarak uyanık ve sedasyon altında veya supraglottik hava yolu araçları ile genel anestezi altında uygulanabilir ${ }^{[9]}$. Sedasyon altında; panik atak, şiddetli öksürük refleksi, hiperkapni, asidoz ortaya çıkması ve yeterli cerrahi görüş açısının sağlanamaması gibi durumlarla karşılaşılabilir ${ }^{[2,10,11]}$.

Bu çalışmada, yarı oturur pozisyonda, küçük tek bir port kullanılarak kamera ve diğer enstrümanların toraks içine alındığı (uniportal) bilateral sempatektomilerde, ÇLT kullanılan klasik entübasyon yöntemi ile Proseal Laringeal Mask Airway (LMA) kullanımıyla spontan solunum korunarak genel anestezi altında uygulanan bir NIVATS tekniğini uygulanabilirlik ve perioperatif etkiler açısından karşılaştırılması amaçlanmıştır.

\section{GEREÇ ve YÖNTEM}

Çalışmamız 3. basamak bir eğitim araştırma hastanesi göğüs cerrahisi ameliyat odasında, prospektif klinik bir araştırma olarak yapıldı. Kurumsal etik kurul onayı alındı. Sempatektomi ameliyatı geçirecek, çalışmaya katılmayı kabul eden ve yazılı onamları alınan, 18-45 yaşları arasında, ASA skoru I-II, vücut kitle indeksi $<35 \mathrm{~kg} / \mathrm{m}^{2}$ olan hastalar çalışmaya dâhil edildi. Orofaringeal ve laringeal malformasyonu olan hastalar çalışmaya dâhil edilmedi. Proseal LMA ile spontan solunum grubu (Grup LMA) ve ÇLT ile entübe kontrol grubu (Grup ÇLT) olmak üzere hastalar 2 gruba ayrıldı. Hastalar; önce Grup LMA, sonra Grup ÇLT olmak üzere sırayla çalışmaya alındı.

Grup LMA'daki hastaların anestezi indüksiyonu 2-3 $\mathrm{mg} / \mathrm{kg}$ propofol ve 0,1-0,2 $\mathrm{mcg} / \mathrm{kg}$ remifentanil ile yapıldıktan sonra Proseal LMA yerleştirildi. Anestezinin idamesinde 1,3 MAC sevofluran kullanılarak spontan solunumun geri gelmesi beklendi. Ameliyat ekibi tarafından port giriş bölgesine $50 \mathrm{mg}$ bupivakain ile interkostal blokaj uygulandı, port yerleştirilerek spontan solunum korunarak iyatrojenik pnömotoraks oluşturuldu. Sempatektomi işlemi bitirildikten sonra portun yanından toraks içine bir aspirasyon sondası gönderildi. Su altı drenajı için sondanın dış ucu böbrek küvet içine doldurulmuş izotonik mayi içine daldırıldı. Anestezi cihazının ayarlanabilir basınç valfi 35-40 $\mathrm{cmH}_{2} \mathrm{O}^{\prime}$ ya ayarlanarak kollabe olan akciğerin anestezi balonu yardımıyla şişirilmesi ve böylelikle toraks içindeki havanın tahliyesi sağlandı. Böbrek küvet içinde kabarcıklar sonlandığında anestezi balonu basılı tutuldu ve akciğer ekpanse hâldeyken aspirasyon sondası çekildi. Sonda çekilir çekilmez sütür bağlanarak toraks tamamen kapatıldı. Kontralateral tarafa geçilirken basınçlı ventilasyon ile spontan solunumu baskılanan hastanın, spontan solunumunun geri gelmesi beklendi ve port giriş bölgesine $50 \mathrm{mg}$ bupivakain ile interkostal blokaj uygulandı. Aynı işlemler sırasıyla kontralateral taraf için de gerçekleştirildi. Intraoperatif olarak $0,5 \mathrm{mg} / \mathrm{kg}$ meperidin ve $1 \mathrm{~g}$ parasetamol uygulandı. Cerrahi bitiminde spontan solunumun geri gelmesi ile Proseal 
LMA çıkarıldı. Proseal LMA malpozisyonunda veya cerrahiye bu şekilde devam edilemeyeceği bir durum oluştuğunda, hastaların çift lümenli tüp ile entübe edilmesi ve çalışma dışı bırakılması planlandı.

Grup ÇLT'deki hastaların anestezi indüksiyonu 2-3 $\mathrm{mg} / \mathrm{kg}$ propofol, $1 \mathrm{mcg} / \mathrm{kg}$ fentanil ve $0,6 \mathrm{mg} / \mathrm{kg}$ roküronyum ile yapıldı. Daha sonra ÇLT ile entübasyon yapıldı. İndüksiyon süresinde ÇLT'nin uygun kısımları klemplenerek akciğer sesleri oskülte edildi ve sonrasında fiberoptik bronkoskop ile tüpün pozisyonu doğrulandı. Anestezinin idamesinde 1,3 MAC sevofluran kullanıldı. ÇLT grubundaki hastalar basınç kontrollü mekanik ventilasyon ile iki akciğer ventilasyonunda $7 \mathrm{~mL} / \mathrm{kg}$, tek akciğer ventilasyonunda ise 5 $\mathrm{mL} / \mathrm{kg}$ TV ve maksimum $\mathrm{EtCO}_{2}$ değeri $45 \mathrm{mmHg}$ olacak şekilde ventile edildi. $\mathrm{FiO}_{2}$ değeri, minimum $\mathrm{SpO}_{2}$ $\% 90$ 'ın altına düşmeyecek şekilde ayarlandı. Ameliyat ekibi tarafından port giriş bölgesine $50 \mathrm{mg}$ bupivakain ile interkostal blokaj uygulandı. ÇLT'nin uygun bölümü klemplenerek akciğer kollapsı sağlandıktan sonra portyerleştirilerektoraksagirildi.Sempatektomi işlemi bitirildikten sonra toraks içindeki havanın tahliyesi Grup LMA'daki gibi sağlandı. Kontralateral port giriş bölgesine $50 \mathrm{mg}$ bupivakain ile interkostal blokaj uygulandıktan sonra diğer işlemler de aynı sırayla yapıldı. İntraoperatif olarak $0,5 \mathrm{mg} / \mathrm{kg}$ meperidin ve $1 \mathrm{~g}$ parasetamol uygulandı. Nöromusküler geri döndürücü ajan olarak 2-4 mg/kg dozunda sugammadeks kullanıldı.

Hastalar cerrahi sonrasında Anestezi Sonrası Bakım Ünitesine (ASBÜ) alındı. ASBÜ'de Numerik Ağrı Skalası (NRS) skoru $\geq 4$ olan hastalara kurtarıcı analjezik olarak $50 \mathrm{mg}$ iV deksketoprofen uygulandı. Deksketoprofen uygulanan hastalarda, NRS $\geq 4$ devam ettiği durumlarda, $0,5 \mathrm{mg} / \mathrm{kg}$ iV meperidin uygulandı. ASBÜ'deki hastaların, Modifiye Aldrete Skoru $\geq 9$ olduğunda servise gönderildi.

Hastaların yaş (yıl), cinsiyet (kadın/erkek), boy $(\mathrm{cm})$, ağılık (kg), BMI $\left(\mathrm{kg} / \mathrm{m}^{2}\right)$ ve ASA fiziksel skoru (I/II) kaydedildi. Ek hastalık varlığı ve ilaç kullanım öyküsü sorgulandı. Kıdemli cerrah tarafından cerrahi zorluk değerlendirdi. Cerrahi zorluk; dört seçenekli (zorluk yok/hafif zorluk/orta zorluk/imkânsız) bir skala ile değerlendirildi. Anestezi indüksiyonu başlangıcı ile hava yolu aracının yerleştirilmesinin tamamlanması arasındaki süre "anestezi indüksiyon süresi", ilk interkostal blokaj ile son cerrahi sütür arasındaki süre "cerrahi süre", cerrahi sonunda anestezi gazın vücuttan boşaltılmaya başlaması ile hastanın komutlara uymaya başlaması arasındaki süre "uyandırma süresi" olarak dk. cinsinden kaydedildi. Ameliyat boyunca end-tidal karbondioksit $\left(\mathrm{EtCO}_{2}-\mathrm{mmHg}\right)$, fraksiyone inspiratuar oksijen konsantrasyonu $\left(\mathrm{FiO}_{2}-\%\right)$, periferal oksijen satürasyonu $\left(\mathrm{SpO}_{2}-\%\right)$, solunum sayısı (SS-soluk/dk.) ve tidal volume (TV-mL) değerleri aralıklı olarak kaydedildi. $\mathrm{EtCO}_{2}$ değerlerinden maksimum olan değer, $\mathrm{FiO}_{2}$ ortalama değeri, $\mathrm{SpO}_{2}$ değerlerinden minimum olan değer, maksimum SS değerleri ve TV değerlerinin ortalamaları karşılaştıııldı.

ASBÜ ve serviste hastaların ağrı şiddeti, nümerik ağrı skalası (NRS) ile 0-10 puan arasında değerlendirildi. ASBÜ'ye geliş ile çıkış arasındaki süre "ASBÜ kalış süresi" olarak değerlendirildi. Ağrısı olan hasta sayısı (var/yok), ağrının şiddeti (hafif/orta/şiddetli), analjezik kullanımı (var/yok) ve ASBÜ kalış süreleri (dk.) kaydedildi.

ASBÜ’ye geliş ile serviste oral beslenmeye başlama zamanı arasındaki süre "oral beslenmeye başlama zamanı", ASBÜ'ye geliş ile serviste mobilizasyona başlama zamanı arasındaki süre "mobilizasyona başlama zamanı" olarak değerlendirildi ve "saat" cinsinden kaydedildi. Mobilizasyona başlama zamanları: 0-3 saat "erken", 4-7 saat "orta", 8-11 saat "geç" olarak sınıflandırıldı. Postoperatif 6 . ve 24 . saatlerdeki NRS ağrı şiddeti (hafif/orta/şiddetli), postoperatif 6 . ve 24. saatlerde boğaz ağrısı (var/yok), postoperatif 6. ve 24. saatlerdeki bulantı veya kusma (var/yok), serviste ek analjezik ihtiyacı (var/yok), hava kaçağı veya pnömotoraks varlığı (var/yok) ve hastaneden taburculuk süresi (gün) kaydedildi.

Benzer bir çalışma olan Irons ve ark.'nın ${ }^{[1]}$ yaptığı "Intubated Versus Nonintubated General Anesthesia 
or Video-Assisted Thoracoscopic Surgery" çalışması baz alınarak güç analizi yapıldı. G Power 3.1 programı ile $\alpha$ değeri 0,05 ve güç değeri $\% 80$ alınarak etki büyüklüğü 1.08 olarak hesaplandı ve her bir grup için örneklem büyüklüğü minimum 15 olarak belirlendi. Tüm verilerin analizi SPSS 25.0 (Statistical Package for Social Sciences Inc; Chicago, IL, ABD) istatistik programı ile değerlendirildi. Tanımlayıcı istatistikler kesikli veriler için sayı ve yüzde olarak, sürekli veriler için ortalama ve standart sapma şeklinde gösterildi. Kesikli verilerin karşılaştırılmasında ki-kare testi uygulandı. ki-kare testi sonucunda, beklenen göz sayısı tüm göz sayısının \%20'sinden daha fazla olması durumunda Fischer'in kesin testi, daha az olması durumunda Pearson ki-Kare testi kullanıldı. Sürekli değişkenlerin normal dağılıma uygunluklarını değerlendirmek amacıyla Kolmogorov-Smirnov testi uygulandı. Bu bağlamda, normal dağılıma sahip sürekli verilere, bağımsız gruplar için Student-T testi, normal dağılım göstermeyen sürekli verilere Mann Whitney $\mathrm{U}$ testi uygulandı. Analiz sonuçları bulgular, tartışma ve sonuç bölümlerinde açıklandı ve istatistiksel anlamlıık sınırı 0,05 olarak kabul edildi.

\section{BULGULAR}

Çalışmamız; bilateral uniportal VATS Sempatektomi uygulanan, 18-41 yaş arasında, ASA I/II, 40 hasta üzerinde yapıldı. Hastaların tanımlayıcı demografik özellikleri, ek hastalıkları ve ilaç kullanımları gruplar arasında benzerdi (Tablo 1).

Anestezi indüksiyon süresi grup LMA da istatistiksel anlamlı olarak daha kısa bulundu $(p<0.01)$ ve diğer intraoperatif sürelerde anlamlı bir farklııı saptanmadı (Tablo 2). Hastaların intraoperatif solunum parametrelerinin karşılaştırmasında gruplar arasında, maksimum $\mathrm{EtCO}_{2}$, ortalama $\mathrm{FiO}_{2}$, minimum $\mathrm{SPO}_{2^{\prime}}$ maksimum SS ve ortalama TV değerlerinde istatistiksel olarak anlamlı fark bulundu $(p<0.01)$ (Tablo 3 ). $\mathrm{SpO}_{2}$ ve $\mathrm{FiO}_{2}$ değerlerinin gruplara göre seyri Şekil 1 'de; solunum sayısı, tidal volüm ve $\mathrm{EtCO}_{2}$ değerlerinin gruplara göre seyri Şekil 2'de gösterilmiştir.

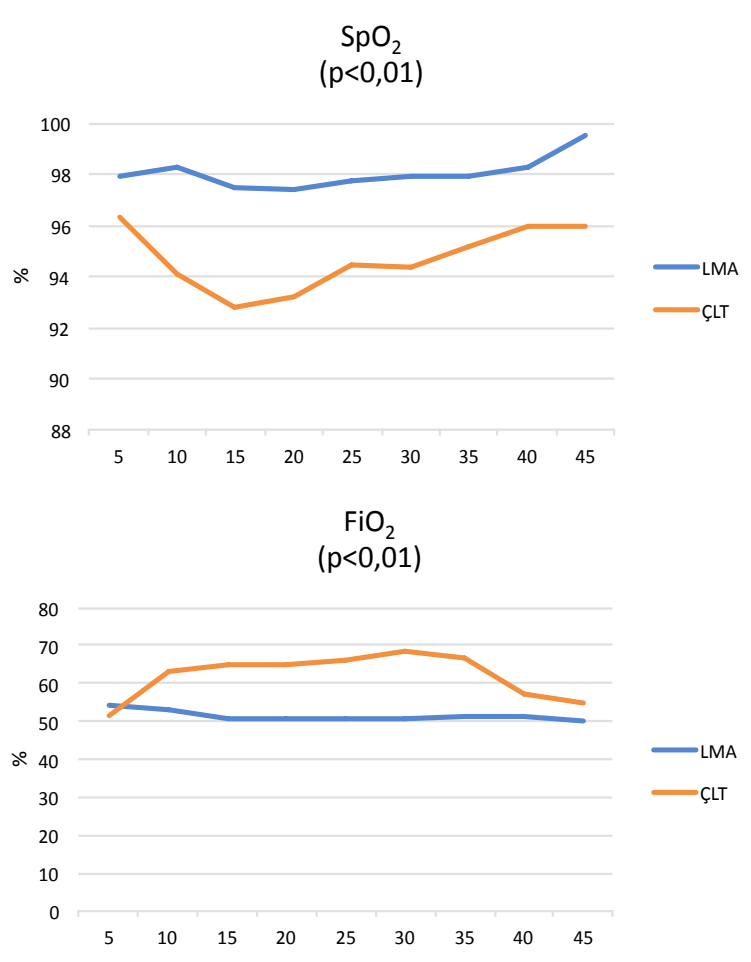

Şekil 1. $\mathrm{SpO}_{2}$ ve $\mathrm{FiO}_{2}$ değerlerinin gruplara göre seyri. ÇLT: Çift lümenli tüp; FiO, Fraksiyone inspiratuar oksijen konsantrasyonu; LMA: Laringeal mask airway; $\mathrm{SpO}_{2}$ : Periferal oksijen satürasyonu

Intraoperatif dönemde cerrahilerin hepsi uniportal ve bilateral olarak gerçekleştirildi. Cerrah tarafından değerlendirilen cerrahi zorluk derecesi dağılımları her 2 grup için benzerdi (Şekil 3).

ASBÜ'de; ağrısı olan hasta sayısı, ağrı şiddeti sınıflaması, analjezik kullan hasta sayısı ve PACU kalış sürelerinde, gruplar arasında istatistiksel olarak anlamlı bir farklılık görülmedi ( $p>0.05$ ) (Tablo 4).

Hastaların oral beslenmeye ve mobilizasyona başlama süreleri, grup LMA'da istatistiksel anlamlı olarak daha kısa olduğu görüldü ( $p<0.01)$. Postoperatif 6 . ve 24. saatlerdeki NRS ağrı şiddeti, boğaz ağrısı, bulantı veya kusma, serviste ek analjezik gereksinimi, hava kaçağı veya pnömotoraks varlığı ve hastaneden taburculuk sürelerinde istatistiksel olarak anlamlı bir farklılık görülmedi ( $p>0.05$ ). Postoperatif dönemde LMA grubunda 1; ÇLT grubunda 3 hastada radyolojik olarak pnömotoraks gösterildi ancak istatistiksel olarak anlamlı değildi (Tablo 5). 
Tablo 1. Demografik özellikler, ek hastalıklar ve ilaç kullanımı.

\begin{tabular}{|c|c|c|c|}
\hline & $\begin{array}{l}\text { LMA grubu } \\
n=20\end{array}$ & $\begin{array}{c}\text { ÇLT grubu } \\
n=20\end{array}$ & p değeri \\
\hline Yaş, (YıI) (OrtıSS) & $27.60 \pm 8.198$ & $27.30 \pm 6.876$ & 0.901 \\
\hline Cinsiyet (Erkek/Kadın), n (\%) & $11 / 9(\% 55 / \% 45)$ & $11 / 9$ (\%55/\%45) & 1.000 \\
\hline Boy, $(\mathrm{cm})$ (Ort $\pm S S)$ & $169.85 \pm 10.409$ & $172.05 \pm 8.642$ & 0.472 \\
\hline Ağırlık, (kg) (OrtıSS) & $67.65 \pm 13.724$ & $71.45 \pm 13.858$ & 0.389 \\
\hline VKi, $\left(\mathrm{kg} / \mathrm{m}^{2}\right)$ (Ort $\left.\pm \mathrm{SS}\right)$ & $23.5205 \pm 4.18724$ & $23.9940 \pm 3.02024$ & 0.684 \\
\hline ASA Fiziksel Skoru, (1/2) n (\%) & 14/6 (\%70/\%30) & $13 / 7$ (\%65/\%35) & 0.736 \\
\hline İnterstisyel akciğer hastalığı & $0(\% 0)$ & $0(\% 0)$ & - \\
\hline KOAH & $0(\% 0)$ & $0(\% 0)$ & - \\
\hline Aritmi & $0(\% 0)$ & $0(\% 0)$ & - \\
\hline DM & $0(\% 0)$ & $0(\% 0)$ & - \\
\hline Steroid inhaler kullanımı & $0(\% 0)$ & $0(\% 0)$ & - \\
\hline İnhaler kullanım & $0(\% 0)$ & $0(\% 0)$ & - \\
\hline Diğer ilaçların kullanımı & $5 / 20(\% 25)$ & $4 / 20(\% 20)$ & 1.000 \\
\hline
\end{tabular}

ASA: American Society of Anesthesiologists; ÇLT: Çift lümenli tüp; DM: Diabetes Mellitus;

KOAH: Kronik Obstrüktif Akciğer Hastalığı; LMA: Laringeal mask airway; VKi: Vücut Kitle Indeksi

\section{Tablo 2. Ameliyat içi süreler (dakika).}

\begin{tabular}{|c|c|c|c|}
\hline & $\begin{array}{c}\text { LMA grubu } \\
n=20 \\
\text { (Ort } \pm S S)\end{array}$ & $\begin{array}{c}\text { ÇLT grubu } \\
n=20 \\
\text { (Ort } \pm S S)\end{array}$ & p değeri \\
\hline Anestezi indüksiyon süresi & $3.05 \pm 1.276$ & $9 \pm 1.835$ & $0.000 *$ \\
\hline Cerrahi süresi & $34 \pm 11.85$ & $29.8 \pm 9.606$ & 0.226 \\
\hline Uyandırma süresi & $7.95 \pm 2.235$ & $8.75 \pm 2.268$ & 0.268 \\
\hline İndüksiyon + cerrahi + uyandırma süresi & $45 \pm 12.286$ & $47.55 \pm 9.747$ & 0.472 \\
\hline
\end{tabular}

\section{ÇLT: Çift lümenli tüp; LMA: Laringeal mask airway; *Mann Whitney-U testi kullanılmıştır.}

Tablo 3. Solunumsal parametreler.

\begin{tabular}{|c|c|c|c|}
\hline & $\begin{array}{l}\text { LMA grubu } \\
\qquad n=20 \\
\text { (Ort } \pm S S)\end{array}$ & $\begin{array}{c}\text { ÇLT grubu } \\
n=20 \\
\text { (Ort } \pm S S)\end{array}$ & p değeri \\
\hline Maksimum EtCO $(\mathrm{mmHg})$ & $42.85 \pm 4.12$ & $36.15 \pm 4.534$ & 0.000 \\
\hline Ortalama $\mathrm{FiO}_{2}(\%)$ & $50.50 \pm 5.104$ & $65 \pm 18.281$ & 0.002 \\
\hline Minimum $\mathrm{SpO}_{2}(\%)$ & $96.25 \pm 3.338$ & $91 \pm 4.779$ & 0.000 \\
\hline Maksimum SS (Soluk/dk.) & $30.25 \pm 6.56$ & $12.75 \pm 1.888$ & 0.000 \\
\hline Ortalama TV (mL) & $219.80 \pm 50.925$ & $317.15 \pm 97.437$ & 0.000 \\
\hline
\end{tabular}

ÇLT: Çift lümenli tüp; EtCO : End-tidal karbondioksit; FiO $:$ Fraksiyone inspiratuar oksijen konsantrasyonu;

LMA: Laringeal mask airway; $\mathrm{SpO}_{2}$ : Periferal oksijen satürasyonu; SS: Solunum sayısI; TV: Tidal volume

\section{Tablo 4. Anestezi sonrası bakım ünitesindeki parametreler.}

\begin{tabular}{|c|c|c|c|}
\hline & $\begin{array}{l}\text { LMA grubu } \\
n=20\end{array}$ & $\begin{array}{l}\text { ÇLT grubu } \\
n=20\end{array}$ & p değeri \\
\hline ASBÜ’de ağrısı olan hasta sayısı, n (\%) & $18(\% 90)$ & $17(\% 85)$ & 1.000 \\
\hline ASBÜ NRS ile ağrı şiddeti değerlendirmesi & & & 0.906 \\
\hline Hafif (0-3), n (\%) & $7(\% 35)$ & $5(\% 25)$ & \\
\hline Orta (4-7), n (\%) & $10(\% 50)$ & $12(\% 60)$ & \\
\hline Şiddetli (8-10), n (\%) & $3(\% 15)$ & 3 (\%15) & \\
\hline ASBÜ analjezik kullanılan hasta sayısı, n (\%) & $13(\% 65)$ & 15 (\%75) & 0.490 \\
\hline ASBÜ kalış süresi (dak.) (OrtıSS) & $38.8 \pm 9.412$ & $41.55 \pm 8.763$ & 0.345 \\
\hline
\end{tabular}

ASBÜ: Anestezi sonrası bakım ünitesi; ÇLT: Çift lümenli tüp; LMA: Laringeal mask airway; NRS: Sayısal derecelendirme skalası 

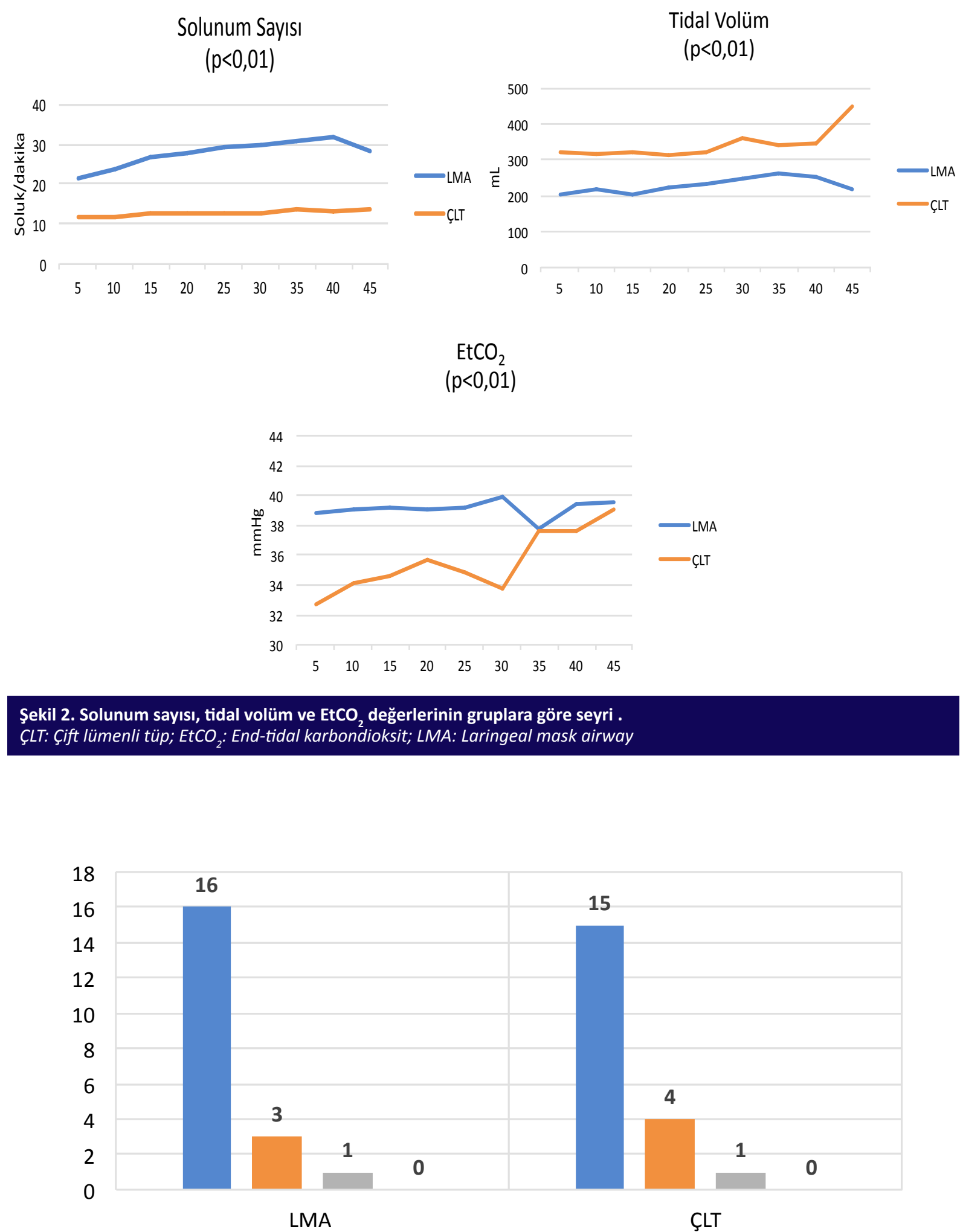

Zorluk Yok Hafif Zorluk Orta Zorluk İmkansız

Şekil 3. Cerrahi zorluk derecesi. 


\begin{tabular}{|c|c|c|c|}
\hline & $\begin{array}{l}\text { LMA grubu } \\
n=20\end{array}$ & $\begin{array}{c}\text { ÇLT grubu } \\
n=20\end{array}$ & p değeri \\
\hline Oral beslenmeye başlama, (saat) (Ort \pm SS) & $4.15 \pm 1.04$ & $5.5 \pm 1.638$ & 0.004 \\
\hline Mobilizasyona başlama, (saat) (Ort $\pm S S$ ) & $4.1 \pm 1.44$ & $5.95 \pm 1.84$ & 0.001 \\
\hline Erken (0-3), n (\%) & $6(\% 30)$ & $1(\% 0)$ & \\
\hline Orta (4-7), n (\%) & $14(\% 70)$ & $15(\% 75)$ & \\
\hline Geç (8-11), n (\%) & $0(\% 0)$ & $4(\% 20)$ & \\
\hline Postop. 6. saat ağrı değerlendirmesi (NRS) & & & 0.144 \\
\hline Hafif $(0-3), \mathrm{n}(\%)$ & $17(\% 85)$ & $19(\% 85)$ & \\
\hline Orta (4-7), n (\%) & $3(\% 15)$ & $1(\% 15)$ & \\
\hline Şiddetli (8-10), n (\%) & $0(\% 0)$ & $0(\% 0)$ & \\
\hline Postop. 6. saat boğaz ağrısı, n (\%) & $2(\% 10)$ & $2(\% 10)$ & 1.000 \\
\hline Postop. 6. saat bulantı-kusma, n (\%) & $0(\% 0)$ & $0(\% 0)$ & - \\
\hline Postop. 24. saat ağrı değerlendirmesi (NRS) & & & 0.605 \\
\hline Hafif (0-3), n (\%) & $19(\% 95)$ & $17(\% 85)$ & \\
\hline Orta (4-7), n (\%) & $1(\% 5)$ & $3(\% 15)$ & \\
\hline Şiddetli (8-10), n (\%) & $0(\% 0)$ & $0(\% 0)$ & \\
\hline Postop. 24. saat boğaz ağrısı, n (\%) & $0(\% 0)$ & $0(\% 0)$ & - \\
\hline Postop. 24. saat bulantı-kusma, n (\%) & $0(\% 0)$ & $0(\% 0)$ & - \\
\hline Postop. ek analjezik gereksinimi, n (\%) & $13(\% 65)$ & $15(\% 75)$ & 0.490 \\
\hline Postop. hava kaçağı, n (\%) & $0(\% 0)$ & $0(\% 0)$ & - \\
\hline Postop. pnömotoraks, n (\%) & $1(\% 5)$ & $3(\% 15)$ & 0.605 \\
\hline Hastaneden taburculuk süresi, (Gün) (Ort $\pm S S$ ) & $1.15 \pm 0.489$ & $1.55 \pm 0.826$ & $0.061^{*}$ \\
\hline
\end{tabular}

ÇLT: Çift lümenli tüp; LMA: Laringeal mask airway; NRS: Sayısal derecelendirme skalasI; Postop: Postoperatif; *Mann Whitney-U testi kullanılmıştır.

\section{TARTIŞMA}

Bu çalışmada, VATS Sempatektomilerde, ÇLT ile uygulanan klasik anestezi tekniğine alternatif olarak Proseal LMA kullanılan NIVATS tekniğinin güvenli şekilde uygulanabilir olduğu gösterilmiştir. LMA NIVATS tekniğinin; daha iyi oksijenizasyon, daha kısa anestezi süreleri, daha erken postoperatif oral alıma başlama ve daha erken mobilizasyon ile ilişkili olduğu görülmüştür.

Çalışmamızda, klasik LMA tercih edilmemiş olup, fleksible ve zırhlı ventilasyon kanalı, gastrik aspirasyon kanalı, ısırma bloğu olması ve daha yüksek hava yolu basınçlarına izin veren (35-40 $\mathrm{cmH}_{2} \mathrm{O}$ ) özelliklerinden dolayı Proseal LMA kullanılmıştır. Bu cerrahinin spontan solunum altında yaptırılması düşünüldügünde, akciğerin paradoksal hareketiyle tam kollabe olmayacağı ve mediastenin pandül hareketi ile cerrahi görüşün yeterince sağlanamayacağı konusunda endişeler mevcuttu. Çalışmamızda, ÇLT grubunda \%25, LMA grubunda \%20 oranında cerrahi zorluk olduğu değerlendirildi. Bu sonuç, LMA ile spontan solunumda toraksın, akciğerlerin ve mediastenin hareketlerinin cerrahi zorluğu ve görüş açısını etkilemediğini göstermektedir. Irons ve ark.'nın ${ }^{[1]}$ yaptıkları çalışmada, NIVATS tekniğinde cerrahi zorluk verileri bulgularımızla benzerdir. LMA ile veya tek lümenli endotrakeal tüp ile aralıklı ventilasyon tekniği uygulanarak cerrahi görüşün sağlandığı çalışmalar da vardır ${ }^{[12,13]}$. Proseal LMA kullanılması ve spontan solunuma olgu boyunca izin verilmesi çalışmamızın söz edilen çalışmalardan temel farkını oluşturmaktadır.

NIVATS tekniği, yaygın olarak sedoanaljezi ya da rejyonal anestezi teknikleri eşliğinde uyanık şekilde uygulanmaktadır. Uyanık NIVATS tekniğinde hastalarda öksürük refleksi oluşabilir ve panik atak ortaya çıkabilir. Çalışmamızda, LMA grubunda genel anestezi tercih edildi. Pompeo ve ark.'nın ${ }^{[14]}$ çalışmasında sedasyon ile birlikte torasik epidural anestezi uygulanmış ve 21 hastanın 3'ünde öksürük gelişmiştir. Diğer yandan, Chen ve ark.'nın ${ }^{[15]}$ çalışmasındaki 30 hastaya sedasyon ve torasik epidural anestezi eşliğinde uyanık NIVATS yapılırken beraberinde intratorasik 
vagus blokajı uygulanması nedeniyle öksürük gözlenmemiştir. Çalışmamızdaki hastalar genel anestezi altında opere olduklarından ve akciğer parankimine bir müdahale olmadığından öksürük görülmediği düşünülmektedir.

Çalışmamızda, yerleştirme ve konfirme etme tekniğinin daha basit olması ve nöromüsküler blokör ajan kullanılmamasına bağlı olarak LMA grubunda anestezi indüksiyon süresi daha kısa gerçekleşti. Her ne kadar 2 grup arasında cerrahi zorluk değerlendirmesinde fark olmasa da cerrahi sürelerin LMA grubunda daha uzun olmasından kaynaklı olarak, anestezi indüksiyon süreleri arasındaki farkın toplam ameliyat süresine anlamlı olarak yansımadığı görüldü. Cui ve ark.'nın ${ }^{[16]}$ çalışmasında, rejyonal anestezi ve tüp torakostomi uygulamalarının katkısıyla toplam ameliyat süreleri çalışmamıza göre daha uzun gerçekleşmiş olabilir. Çalışmamızda, her 2 grupta da toraks drenaj tüpü ve anestezi yönetiminde rejyonal anestezi kullanılmadı. Sonuçta, çalışmamızdaki amaç süreleri kısaltmak değil, LMA gibi supraglottik bir araçla VATS olgularının güvenli ve başarılı bir şekilde yaptırılabildiğini göstermekti. ÇLT grubuyla benzer sürelerde olguların tamamlanmış olmasının değerli olduğu düşünülmektedir.

NIVATS tekniğinde yetersiz solunum ile hiperkapni ve asidoz gelişebilir ${ }^{[10,11]}$. Solunum parametreleri karşılaştırıldığında, kontrollü solutulan ÇLT grubuna oranla LMA grubunda, maksimum SS ve $\mathrm{EtCO}_{2}$ değerlerinin daha yüksek, ortalama TV'lerin ise daha düşük gözlenmesinin spontan yüzeyel soluma nedeniyle olduğu anlaşılmaktadır. Lai ve ark.'nın ${ }^{[2]}$ torasik epidural anestezi eşliğinde sevoflurane ile propofol+sevoflurane anestezik kombinasyonlarını karşılaştırdıkları çalışmalarında, spontan solunumda LMA ile VATS yapılan hastalarda solunum sayısı çalışmamıza göre düşüktür. Bu farkın çalışmamıza oranla daha etkin analjezi uygulamalarından kaynaklanabileceğini düşünülmektedir. LMA grubunda, ortalama $\mathrm{FiO}_{2}$ daha düşük ve ortalama minimum $\mathrm{SpO}_{2}$ daha yüksek bulunmuştur. İyatrojenik pnömotoraks gerçekleştikten sonra opere edilen taraftaki akciğerin paradoksik solunumla ekspiryumda da kısmen ventile olması ve spontan solunum sırasında kardiyak outputun artmasıyla perifere iletilebilen oksijen miktarında artış bu duruma katkıda bulunmuş olabilir ${ }^{[17]}$.

LMA grubunda hiçbir hastada entübasyon gereksinimi olmadı. Yine, cerrahi görüşün iyileştirilmesi amacıyla her 2 grupta hiçbir hastada torakotomiye geçilmedi. Cui ve ark.'nın ${ }^{[16]}$ çalışmasında, NIVATS Sempatektomi grubunda 59 hasta içerisinden birinde entübasyon gerektiği; yine Chen ve ark.'nın [15] çalışmasında, torasik epidural anestezi ile yapılan 30 NIVATS olgusundan 3'ünde entübasyon gereksinimi olduğu görülmektedir. Bu çalışmalarda, akciğer parankim ameliyatları olması nedeniyle öksürük refleksinin ortaya çıkmasının entübasyon ve kontrollü solunum gereksinimini doğurduğu düşünülmektedir. Irons ve ark.'nın ${ }^{[1]}$ çalışmasında ise, çalışmamıza benzer şekilde NIVATS grubuna dâhil edilen 31 hastada entübasyon ve torakotomi gereksinimi olmadığı görülmektedir.

İki grup arasında oral beslenmeye başlama ve mobilizasyona başlanma zamanlarında istatistiksel olarak anlamlı fark görüldü. LMA grubunda, nöromüsküler blokör ve geri döndürücü ajan kullanılmaması gruplar arasındaki bu farka sebep olmuş olabilir. Benzer şekilde, Cui ve ark.'nın ${ }^{[16]}$ çalışmasında da rejyonal NIVATS grubunda ÇLT grubuna göre oral alım zamanı anlamlı olarak daha kısadır.

Postoperatif pnömotoraks ek tetkik ve işlem gereksinimi oluşturmaktadır. Bu nedenle postoperatif konfor ve hastanede kalış süresini etkileyebilir. Çalışmamızda, LMA grubunda 1, ÇLT grubunda 3 hastada postoperatif pnömotoraks belirlendi. Caviezel ve ark.'nın ${ }^{[8]}$ çalışmasında, NIVATS Sempatektomi grubunda 10 hastadan 5'inde, VATS Sempatektomi grubunda 10 hastadan 3'ünde pnömotoraks belirlenmiştir. İlgili çalışmada rejyonal anestezi ve sedasyon altında uygulanan NIVATS'larda, hastalardan akciğer ekspansiyonu için derin nefes alması veya öksürmesi istenememiş; bu nedenle toraks içine bir sonda yerleştirilerek cerrahi aspiratör yardımıyla toraks içinde- 
ki havanın tahliyesi sağlanmıştır. Çalışmamızda, akciğer ekspansiyonu anestezi balonu kullanılarak sağlandı ve hem Proseal LMA hem de ÇLT grubunda $35-40 \mathrm{cmH}_{2} \mathrm{O}$ hava yolu basınçları etkili bir şekilde kullanıldı. Bu nedenle, kontrollü ventilasyon uygulanabilirliği LMA ile NIVATS tekniğinin üstünlüğü olarak değerlendirilebilir.

LMA ile NIVATS tekniğinde kontrollü ventilasyon uygulanamadığından tidal volüm, solunum sayısı, hava yolu basıncı gibi parametreler anesteziyolog tarafından ayarlanamamaktadır. Bu durum ameliyat sırasında belirtilen parametrelerde değişkenlik yaratmaktadır. Hastaların sık ve yüzeyel solunum paterninde ventilasyonunun, ameliyatın uzaması hâlinde solunum iş yükün arttıracağı, diafragma ve yardımcı solunum kaslarında yorulmaya yola açabileceği ve postoperatif dönemde akciğer üzerinde atelektazik alanlar yaratabileceği öngörülmüştür. Fakat çalışmamızda, gerek genç yaş grubu hastaların bulunması, gerek ameliyat süresinin kısa olması nedeniyle bu tür komplikasyonlarla karşılaşılmamış olabileceği düşünülmektedir.

Çalışmamızın kısıtlılıkları içinde, randomizasyon ve körleme yapılmaması, tek merkezde sınırlı sayıda vakada yapılmış olması ve cerrahi uygulanabilirliği değerlendiren birden fazla cerrah olması sıralanabilir.

Bu çalışmada, uniportal VATS Sempatektomilerde ve yarı oturur pozisyonda, Proseal LMA'nın spontan solunum korunarak, iyatrojenik açık pnömotoraks tekniği ile etkili ve güvenli bir şekilde uygulanabilir olduğu gösterilmiştir ve alternatif bir yöntem olarak kullanılabilir. Uniportal ve bilateral sempatektomilerde LMA tekniğiyle hava yolu ile ilgili girişimsel işlemler azaltılarak perioperatif dönemde mobilizasyon ve oral alım daha erken dönemlerde sağlanabilir Oluşabilecek komplikasyonların ve sorunların giderildiği daha büyük serilerde çalışmalara gereksinim olduğu düşünülmektedir.

\section{KAYNAKLAR}

1. Irons JF, Miles LF, Joshi KR, Klein AA, Scarci M, Solli P, vd. Intubated versus nonintubated general anesthesia for video-assisted thoracoscopic surgery-A case-control study. J Cardiothorac Vasc Anesth [Internet]. Nisan 2017;31(2):411-7. https://doi.org/10.1053/j.jvca.2016.07.003

2. Lai HC, Huang TW, Tseng WC, Lin WL, Chang H, Wu ZF. Sevoflurane is an effective adjuvant to propofol-based total intravenous anesthesia for attenuating cough reflex in nonintubated video-assisted thoracoscopic surgery. Medicine (Baltimore) [Internet]. Ekim 2018;97(42):e12927.

https://doi.org/10.1097/MD.0000000000012927

3. Knoll H, Ziegeler S, Schreiber J-U, Buchinger H, Bialas P, Semyonov $\mathrm{K}$, et al. Airway injuries after one-lung ventilation: A comparison between double-lumen tube and endobronchial blocker. Anesthesiology [Internet]. Eylül 2006;105(3):471-7. https://doi.org/10.1097/00000542-200609000-00009

4. Lohser J, Slinger P. Lung injury after one-lung ventilation. Anesth Analg [Internet]. Ağustos 2015;121(2):30218. https://doi.org/10.1213/ANE.0000000000000808

5. Soto R. Incidence and risk factors for postoperative residual neuromuscular blockade. Curr Anesthesiol Rep [Internet]. 2020; https://doi.org/10.1007/s40140-020-00386-6

6. Murphy GS, Szokol JW, Avram MJ, Greenberg SB, Shear $\mathrm{T}$, Vender JS, et al. Postoperative residual neuromuscular blockade is associated with impaired clinical recovery. Anesth Analg. 2013;117(1):133-41. https://doi.org/10.1213/ANE.0b013e3182742e75

7. van de Pas JM, Van Der Woude MCE, Belgers HJ, Hulsewé KWE, de Loos ER. Bronchus perforation by EZ-blockertm endobronchial blocker during esophageal resection after neoadjuvant chemoradiation - A case report. Korean J Anesthesiol. 2019;72(2):184-7. https://doi.org/10.4097/kja.d.18.00237

8. Caviezel C, Schuepbach R, Grande B, Opitz I, Zalunardo $\mathrm{M}$, Weder W, et al. Establishing a non-intubated thoracoscopic surgery programme for bilateral uniportal sympathectomy. Swiss Med Wkly. 2019;149(1516):1-8. https://doi.org/10.4414/smw.2019.20064

9. Irons JF, Martinez G. Anaesthetic considerations for non-intubated thoracic surgery. J Vis Surg. 2016;2(1): 61-1. https://doi.org/10.21037/jovs.2016.02.22

10. Liu YJ, Hung MH, Hsu HH, Chen JS, Cheng YJ. Effects on respiration of nonintubated anesthesia in thoracoscopic surgery under spontaneous ventilation. Ann Transl Med. 2015;3(8):1-7. https://doi.org/10.3978/j.issn.2305-5839.2015.04.15

11. Wang B, Ge S. Nonintubated anesthesia for thoracic surgery. J Thorac Dis. 2014;6(12):1868-74. 
https://doi.org/10.3978/j.issn.2072-1439.2014.11.39

12. Cesur EE. Non-entubated bilateral single port endoscopic thoracic sympathectomy. South Clin Istanbul Eurasia [Internet]. 2018;29(1):49-52.

https://doi.org/10.14744/scie.2018.02986

13. Kaplan T, Ekmekçi P, Koçer B, Han S. Bilateral sympathicotomy for hyperhidrosis without using single-lung ventilation. TURKISH J Med Sci [Internet]. 2015;45(4):771-4. https://doi.org/10.3906/sag-1405-51

14. Pompeo E, Tacconi F, Mineo D, Mineo TC. The role of awake video-assisted thoracoscopic surgery in spontaneous pneumothorax. J Thorac Cardiovasc Surg. 2007. https://doi.org/10.1016/j.jtcvs.2006.11.001

15. Chen JS, Cheng YJ, Hung MH, Tseng YD, Chen KC, Lee
YC. Nonintubated thoracoscopic lobectomy for lung cancer. Ann Surg. 2011;254(6):1038-43.

https://doi.org/10.1097/SLA.0b013e31822ed19b

16. Cui F, Liu J, Li S, Yin W, Xin X, Shao W, vd. Tubeless video-assisted thoracoscopic surgery (VATS) under non-intubated, intravenous anesthesia with spontaneous ventilation and no placement of chest tube postoperatively. J Thorac Dis [Internet]. Ağustos 2016;8(8): 2226-32.

https://doi.org/10.21037/jtd.2016.08.02

17. Magnusson L. Role of spontaneous and assisted ventilation during general anaesthesia. Best Pract Res Clin Anaesthesiol [Internet]. 2010;24(2):243-52. https://doi.org/10.1016/j.bpa.2010.02.008 